\title{
PESQUTSA PARTICIPANTE NA INTERVENÇÃO DA TRANSMISSÃO DE HELMINTOSES INTESTINAIS (CIDADE SATÉLITE DO PARANOÁ - DISTRITO FEDERAL)
}

\author{
Dalva A. Mello, Cristina B. Martins, Augusto Cesar Bittencourt Jr, Rosa M. \\ C. de Matos, Fausto Pina e Zeedivaldo A. Miranda*
}

\begin{abstract}
Neste trabalbo, desenvolvido na Cidade Satélite do Paranoá/DF, pretende-se desenvolver um projeto de pesquisa participante que contribuisse para a redução dos indices de infecção de belmintoses intestinais em um grupo de crianças de risco nutricional. A unidade da pesquisa foi o Núcleo Familiar que compreendia pais, filhos $e$ outros parentes que babitaviam a mesma residência. Um conjunto de açôes instrumentais técnicas e de processos educativos acompanbaram todas as etapas do projeto. As práticas foram participativas, problematizadoras, estimulantes a análises e reflexōes criticas, objetivando a construção, socialização e apropriação de um novo saber. As ações técnicas compreenderam os exames fecais e tratamento. As ações educativas, tiveram como principio a pedagogia problematizadora estimulante a análises e reflexōes críticas, tendo por eixo condutor a Promoção à Saúde como Qualidade de Vida e Cidadania. O programa dessas ações compreendeu: visitas domiciliares, aplicação de questionário, reuniões de grupos até a entrega dos resultados dos exames e tratamento. Procurou-se resgatar no Tema Gerador a História dos Individuos e da Comunidade, Identificação e Reflexão dos Problemas do Paranoá; Confronto da Realidade Vivenciada. Um conjunto de métodos e técnicas pedagógicas estimulantes à participação foram utilizados. Os processos avaliativos foram: quantitativos - avaliação dos indices de infecção e nümero de participantes; qualitativos - ocorrendo durante todo o desenvolvimento do processo educativo, sendo traduzidos através do material produzido pelos participantes, dos depoimentos individuais e da presença ativa nas etapas e tarefas práticas dos trabalhos nas reuniões. Os resultados obtidos foram relevantes quanto à participação, à produção $e$ apropriaçâo de conbecimentos e na intervenção da transmissão das belmintoses intestinais.
\end{abstract}

Palauras-chaves: Parasitoses intestinais. Epidemiologia e controle das parasitoses intestinais. Educação em Saüde.

As helmintoses intestinais (HI) são ainda consideradas como nosologias de repercussões importantes à saúde humana principalmente na idade escolar onde são encontrados os índices de prevalência mais elevados. Na primeira reunião internacional sobre a campanha "Educação Básica para Todos", realizada em Estocolmo em 1989 e promovida pela UNESCO ${ }^{10}$, tendo por tema central Saúde, Nutrição e Performance Escolar, as HI foram consideradas como primeiro alvo para ações imediatas de intervenção. Esse

\footnotetext{
Departamento de Patologia/Faculdade de Ciências da Saúde da Universidade de Brasilia, DF

Auxílio - Decanato de Extensão/UnB e CNPq Proc. 500833/92-94

Endereço para correspondência: Prof Dalva A. Mello. HCGN 709 Bloco K Casa 29, Asa Norte 70750-711 Brasília, DF.

Recebido para publicação em 27/07/94.
}

aspecto foi justificado por ser considerado importante a associação dessas parasitoses à deficiências de ordem nutricional e a baixa performance escolar.

De uma maneira geral, alguns pesquisadores que vêm trabalhando em controle de $\mathrm{HI}$ tem recomendado programas de desparasitização periódica, 2 a 3 vezes ao ano, considerando o fato de existir drogas eficazes e polivalentes 145791011 . No entanto é fundamental lembrar que os fatores determinantes da prevalência são complexos pois estão diretamente relacionados à aspectos sociais, econômicos e culturais.

Recentemente, considerações econômicas sobre o controle das helmintoses ${ }^{8}$ destacaram como ponto relevante o alto custo financeiro da quimioterapia em massa. Entretanto, esse instrumento quando aplicado através do sistema escolar contribui substancialmente para a redução da prevalência, e por se tratar 
Mello DA, Martins CB, Bittencourt Jr AC, Matos RMC, Pina F, Miranda ZA. Pesquisa participante na intervenção da transmissão de belmitoses intestinais (Cidade Satélite do Paranoá-Distrito Federal). Revista da Sociedade Brasileira de Medicina Tropical 28:223-232, jul-set, 1995.

de campanhas amplas, é sugerido como estratégia amenizante para redução de custos, a integração com os Serviços de Saúde. Essas considerações destacam ainda a importância em se valorizar a percepção que a comunidade tem sobre a doença.

Nesse contexto, é ainda atual considerar como importante, as recomendações da Organização Mundial da Saúde ${ }^{16}$ quanto à participação da população no controle destas parasitoses, de forma dinâmica e "conscientemente engajada no planejamento, implantação, monitoração e avaliação".

No Brasil, algumas experiências em área rural no interior de São Paulo, foram conduzidas nesta linha com sucesso, demonstrando a importância de se integrar além de medidas técnicas de controle em HI, processos de ações educativas e participativas ${ }^{14}$ 151718 .

A idéia do presente trabalho surgiu, por um lado, da nossa preocupação com a contínua infecção e reinfecção por $\mathrm{HI}$ em crianças desnutridas no Paranoá/DF, e por outro, pela demanda dos participantes do Curso de Treinamento de Vigilantes Comunitários, que destacaram a necessidade de se fazer "alguma coisa com verminose" identificando-a diretamente associada "à diarréia, bronquite e à tosse" sintomas considerados entre os problemas de Saúde mais importantes que afetam as crianças dessa comunidade ${ }^{20}$.

Aceitando como desafio o encaminhamento acima e considerando a importância do tema, justificamos nosso objetivo em desenvolver um projeto de pesquisa participante que contribuísse para a redução dos índices de prevalência de HI em um grupo de crianças de risco nutricional. Destacamos que este projeto fazia parte de um programa integrado de Ensino-PesquisaExtensão sobre "Promoção Integral de SaúdeNutrição na Comunidade do Paranoá/DF".

\section{MATERIAL E MÉTODOS}

\section{Local de Trabalho}

O trabalho foi realizado no período de julho de 1991 a outubro de 1993, na cidade satélite do Paranoá/DF que fica situada a cerca de $20 \mathrm{~km}$ do Plano Piloto onde vivem aproximadamente 50.000 habitantes. O Paranoá tem uma história rica de lutas, através de seus movimentos populares organizados, pelos seus direitos sociais e qualidade de vida. As condições ambientais e sanitárias da cidade no período em que a pesquisa foi desenvolvida, eram ainda bastante precárias.

\section{Desenvolvimento Metodológico do Trabalho}

O trabalho foi desenvolvido tendo como eixo condutor os princípios da pesquisa participante ${ }^{3}$. Após discussões e análises conjunta da equipe do programa "Promoção Integral de Saúde-Nutrição na Comunidade do Paranoá/DF" foi definido que a unidade de pesquisa compreenderia o Núcleo Familiar cujas crianças de $0-5$ anos, estavam cadastradas no SEREN (Serviço de Recuperação Nutricional do Centro de Saúde № 15), como de Risco Nutricional. Esse Núcleo Familiar compreendia os pais, filhos, e outros parentes que habitavam a mesma residência, que seriam os sujeitos participantes da pesquisa.

O projeto foi conduzido em três fases: Preparatório (6 meses), Operacional (16 meses) e de Avaliação ( 4 meses).

A Fase Preparatória correspondeu a organização e elaboração detalhada dos protocolos do Projeto, incluindo treinamento de pessoal e padronização de toda a metodologia. Durante esta fase foram realizados vários encontros da equipe para aprofundar as discussões sobre o projeto quanto ao processo de abordagem da Unidade de Pesquisa. Aos agentes de Saúde, coube a responsabilidade da articulação com os responsáveis dos núcleos familiares participantes da pesquisa, para $o$ agendamento das reuniões necessárias ao desenvolvimento dos trabalhos tanto no plano individual (aplicação de questionário, coleta do material fecal) quanto no grupal (reuniões com as famílias por conjuntos de quadras). O papel dos agentes de Saúde foi de fundamental importância como facilitador para a interação da equipe e participantes da pesquisa.

A Fase Operacional compreendeu todo o período de execução da pesquisa que foi desenvolvida processualmente. Considerando a dispersão e distância das residências da Unidade de Pesquisa, para facilitar a locomoção e participação das pessoas, dispusemos os endereços por conjuntos de 
Mello DA, Martins CB, Bittencourt Jr AC, Matos RMC, Pina F, Miranda ZA. Pesquisa participante na intervenção da transmissão de belmitoses intestinais (Cidade Satélite do Paranoá - Distrito Federal). Revista da Sociedade Brasileira de Medicina Tropical 28:223-232, jul-set, 1995.

quadras e aglomeramos os participantesSujeito da pesquisa em dois Grupos, I e II, como segue:

\begin{tabular}{clc} 
Grupos & \multicolumn{1}{c}{ Quadras } & No de Famílias \\
I & 28 (etapa piloto) & 9 \\
& $6,8,10,12 \mathrm{e}$ & 19 \\
& $9,13,15,17,19,21,23,25,27$ & 15 \\
II & $14,16,18,20,22,26,30,32$ & \\
& (controle) & $\frac{11}{54}$
\end{tabular}

No Grupo I, a quadra 28 correspondeu a etapa piloto do trabalho onde foi feito o teste e padronização dos protocolos e toda metodologia da pesquisa. O Grupo II correspondeu ao grupo controle em relação as ações educativas em reuniões. Esse grupo participou do questionário, dos levantamentos coprológicos e tratamentos igualmente aos outros grupos, porém as ações educativas só foram implementadas após o segundo levantamento coprológico, uma vez que se tinha por objetivo checar o impacto das mesmas.

Aplicação do Questionário - Para aplicação do questionário, foram feitas visitas domiciliares em uma amostra de $57,5 \%$ das Unidades da pesquisa (54 residências). Esse questionário foi $o$ instrumento básico informativo que: a) permitiu a equipe compreender a percepção, a linguagem, nível de informações e a visão sobre as HI; e b) foi facilitador às relações sociais entre a equipe e - grupo participante. O questionário era respondido por pais ou responsáveis das crianças da Unidade da Pesquisa.

A visita domicilar foi o momento do início da interação da Equipe e Unidade de Pesquisa. $O$ questionário, que continha perguntas abertas e fechadas, foi adaptado de experiência anterior de uma pesquisa, desenvolvida em área rural, sobre o mesmo tema $^{12}$, abordando: importância, conhecimento sobre as espécies, ciclo evolutivo, aspectos clínicos e epidemiológicos, tratamento, prevenção e controle.

Após sua aplicação, distribuia-se os recipientes contendo conservante MIF, acompanhados de instruções orientadoras para o. procedimento da coleta do material fecal, que eram ainda reforçadas por explicações orais passadas diretamente aos responsáveis pelo agente de saúde ou outro membro da equipe. A coleta de fezes era feita das crianças de $0-12$ anos.

\section{Pesquisa do material fecal e tratamento} - O método utilizado para pesquisa dos parasitas foi o de sedimentação espontânea. $\mathrm{O}$ exame era realizado em duas amostragens de cada coleta, sendo repetido quando negativo.

Os casos positivos eram tratados de acordo com a espécie de parasita identificada, no primeiro e segundo (seis meses após) levantamentos coprológicos. O primeiro levantamento correspondeu a Fase 1 e o segundo a Fase 2.

Os medicamentos utilizados para o tratamento das HI foram o mebendazol e o metronidazol em um esquema de acordo com as orientações padrões do serviço de pediatria do Hospital da Universidade de Brasília (Dra. Vera Bezerra).

Os medicamentos eram entregues diretamente a mãe ou outro responsável pela criança, junto com o resultado do exame, no final de programa educativo. Neste momento, sentavam-se juntos - um monitor com a mãe ou outro responsável - onde eram passadas as explicações sobre os resultados obtidos, e as orientações quanto à dosagem. Esse procedimento proporcionava o repasse dos conhecimentos das causas e determinantes das parasitoses dignósticadas, a exemplo da falta de saneamento completo, asfalto, coleta de lixo etc.

Metodologia do processo educativo - $O$ processo educativo-se derramou por todas as etapas de desenvolvimento do trabalho, isto é desde as visitas domiciliares pelos agentes de saúde e os monitores, durante a aplicação dos questionários e nas reuniões grupais, até a entrega dos resultados dos exames e a medicação.

Durante o período em que estavam sendo realizados os exames coprológicos (à exceção do Grupo II), os agentes de Saúde iniciavam novas visitas aos domícilios para o agendamento das reuniões, que tinham por objetivo trabalhar, com os participantes, o processo educativo relacionado à socialização e apropriação do saber científico e técnico, interagindo com o saber popular. 
Mello DA, Martins CB, Bittencourt Jr AC, Matos RMC, Pina F, Miranda ZA. Pesquisa participante na intervenção da transmissão de belmitoses intestinais (Cidade Satélite do Paranoá - Distrito Federal). Revista da Sociedade Brasileria de Medicina Tropical 28:223-232, jul-set, 1995.

As reuniōes ocorriam, ou na semana normal de trabalho à noite, com duração de duas horas, ou no final da semana no período da tarde com duração de três horas.

As práticas educativas eram conduzidas através de um processo participativo e problematizador $^{2}$ estimulante a análises $e$ reflexões críticas, à valorização do indivíduo, da solidariedade e enfatizando o papel de cada um na comunidade como agente multiplicador e disseminador de conhecimentos, informações e de ações intervencionais. Para a consecução dessas práticas, foi elaborado um programa eixo norteador, com uma pauta básica tendo por princípio a Promoção à Saúde, esta entendida como Qualidade de Vida ${ }^{13}$. O conteúdo do programa foi como segue: história dos indivíduos e da comunidade; identificação, discussão e reflexão sobre os problemas do Paranoá; confronto da realidade vivenciada de cada um e a busca de caminhos para ações; discussões e reflexões sobre a Saúde no Paranoá; o Tema Gerador - compreensão do corpo humano; presença dos vermes e saúde: suas causas, freqüência, conseqüências, tratamento, prevenção e promoção; identificação e tratamento dos vermes (pesquisa no laboratório e tipos de medicamentos e esquemas de como usá-los nas crianças).

Duas abordagens pedagógicas, de forma simultânea e interativa foram utilizadas:

a) Informal - Dominante em todo o processo educativo, foi aplicada com o auxílio de vários métodos e técnicas pedagógicas animadoras e facilitadoras à participação, como seguem:

1. Dramatização - Consistia na criação e interpretação de situações vivenciadas pelos participantes na comunidade. Esse método facilitava a desinibição e o desbloqueio dos participantes, expondo sua percepção em relação à situação dramatizada. Os grupos eram divididos em subgrupos cada um dramatizando coletivamente ou através de depoimentos estimulados e espontâneos; a Situação-Problema. Em seguida era feita a reflexão coletiva das exposições, nas quais era revelada a história de vida de cada participante. Seguindo esse processo de trabalho os problemas afetos à comunidade como um todo, eram explicitados de forma clara e objetiva.
2. Mapa Falante - Como método que faz parte da investigação participativa, implementado nos anos 70 pela "Fundação Colombia Nuestra" em numerosos projetos de educação de camponeses na América Latina, o "mapa que faz falar" consiste basicamente de uma representação, na qual se integram elementos geográficos e de meio ambiente, às habitações e famílias, serviços públicos, conceitos etc. De acordo com o tema, cartazes murais são ilustrados coletivamente com desenhos que representam fenômenos ou dinâmica de processos $^{19}$. Os materiais utilizados para a sua confecção são: papéis do tamanho apropriado (entre $1 \mathrm{~m} \times 1 \mathrm{~m}$ ou mais) para o trabalho de grupo, papéis pequenos para realizar desenhos com lápis de cor, tesouras, fita adesiva etc. Para trabalhar com o Mapa Falante - grupo era divido em subgrupos que trabalhavam em separado. Uma vez elaborados, os mapas eram expostos de forma que todos tivessem acesso ao conhecimento produzido, passando-se em seguida a análises e discussões coletivas no confronto de situações e na relação de causas e efeitos e suas interações. Com a coordenação de um ou mais membros da equipe era feita uma animação buscando incentivar os participantes a se posicionarem com opiniões e críticas, análises situacionais individual e/ou coletiva.

3. Demonstrações Práticas - envolveram exposições dos vermes - fixados em lâminas ou guardados em vidro em líquido conservante; - utilização do microscópio na pesquisa e identificação dos vermes; e demonstração do método coprológico utilizado no trabalho.

4. Registro em Video - foi realizada em uma etapa do processo educativo (total de cinco reuniôes) tendo as seguintes finalidades: a) registrar a atividade como memória; b) dar um retorno aos participantes e equipe do trabalho realizado; e c) contribuir com elementos avaliativos tanto para a equipe quanto para os participantes.

5. Diapositivos e Cartazes - Utilizados para apresentar os temas relacionados às $\mathrm{HI}$, o Paranoá e as Condições de Vida - objetivando estimulação para discussões, análises e critérios assim como à consolidação das informações.

b) Formal - Essa abordagem foi inserida em determinados momentos, compreendendo aulas expositivas sobre assuntos muito 
Mello DA, Martins CB, Bittencourt Jr AC, Matos RMC, Pina F, Miranda ZA. Pesquisa participante na intervenção da transmissão de belmitoses intestinais (Cidade Satélite do Paranoá - Distrito Federal). Revista da Sociedade Brasileira de Medicina Tropical 28:223-232, jul-set, 1995.

específicos. Foi utilizada de forma limitada já que é sabido ser uma metodologia passiva na transmissão de conhecimentos, embora algumas vezes seja útil para intercalar e integrar à Metodologia Informal, objetivando consolidação de conceitos.

Avaliação - A avaliação foi quantitativa em alguns aspectos, mas predominantemente qualitativa também de forma processual, contínua e ao final das reuniões grupais. Como instrumental auxiliar utilizamos os resultados obtidos através de: Mapa Falante; Registro em Vídeo; Depoimentos pessoais estimulados (autoavaliação); Participação, Iniciativa e Interesse nas Reuniões (observação monitorada); Receptividade às Visitas Domiciliares e as Respostas aos Questionários; e, finalmente, os Resultados dos Exames Parasitológicos (antes e depois do tratamento).

\section{RESULTADOS E DISCUSSÃO}

\section{Questionário}

Foram planejados, aplicados e respondidos 31 questionários por 30 mães e 1 pai, indicando um alto grau de interesse pelo trabalho.

Do total de entrevistados $28 \quad(90,3 \%)$ responderam que conheciam os "vermes" ou "lombrigas" e $24(77,4 \%)$ identificaram que os mesmos se localizavam na "barriga" e que procuravam dar às crianças os medicamentos recomendados no Centro de Saúde pelos médicos ou então nas farmácias. É importante destacar que apesar da freqüência mencionada com que as pessoas procuravam o Centro de Saúde para este fim, apenas $9(2,9 \%)$ lembravam de nomes de medicamentos identificando-os como sendo: mebendazol (6), metronidazol (2), ascaridil e rarical (1). Esse aspecto nos fez refletir quanto à dependência do Serviço de Saúde face a um problema que poderia ser resolvido por agentes de saúde que estivessem preparados para o tema, quando em suas visitas domiciliares. Merece comentarmos que não entendendo porque as crianças continuavam sempre infectadas com os vermes, - "mesmo sempre indo ao Centro de Saúde e tomando os remédios que o doutor passava" - as mães se sentiam desanimadas e acreditavam que os medicamentos "pareciam não fazer mais efeito". Assim algumas vezes, essas mães recorriam a um receituário bastante diverso no uso de plantas, seja em forma de chás ou de infusões, indentificando-as como: batata pulga, marcela, losna, casca de laranja torrada, licor de cacau, capim santo, poejo, mastruz com leite, alho com leite, hortelã, semente de abóbora e semente e flor de mamão.

Em relação aos sinais e sintomas (associados ou não) as respostas com mais ênfase e freqüência foram: barriga grande, diarréia - 11 respostas cada; amarelão - 10; necessidade de comer doce - 8 ; dor de barriga - 7; vômitos - 5; e hábito de comer terra - 4.

Todas as pessoas entrevistadas destacaram que os fatores importantes na manutenção da infecção pelos "vermes" estavam associados à terra, poeira e lama; esgoto "correndo" nas ruas; e precariedade na coleta de lixo.

Outras respostas relacionadas à manutenção da infecção se referiram às dificuldades em relação ao controle comportamental da própria criança. Poderíamos ilustrar esse aspecto com as seguintes informações encaminhadas pelas mães: "a própria causa é a criança que não sabe o que faz e é mais complicado para controlar pois brincam muito com a terra"; "quando parei de trabalhar eles diminuíram (os vermes), não deixo sujeira e os meninos comem melhor"; "seguro os meninos em casa, mas não tem jeito pois o piso da casa é de terra"; "tranco os meninos dentro de casa não deixo sair". É importante destacar o fato de que $54,6 \%$ das mães trabalharem fora, em sua grande maioria $(88,3 \%)$, como domésticas diaristas.

No aspecto geral das residências, tanto no peridomiçílio quanto no intradomicílio, verificou-se grande precariedade no que se refere às condições de higiene. Assim é que: apenas, 6 cąsas foram identificadas em condições boas de higiene; 5 em condições apenas razoáveis; e as 20 restantes em condições totalmente precárias. Não obstante este quadro, 30 residências tinham água encanada e 29 fossa.

Fazendo uma análise das perguntas do questionário, relacionadas ao ciclo evolutivo, a transmissão, epidemiologia, controle e prevenção, verificamos uma fragmentação muito grande de conteúdo processual. Assim é que as mães conseguiram apenas identificar as HI: etiologicamente como sendo "vermes"ou 
Mello DA, Martins CB, Bittencourt Ir AC, Matos RMC, Pina F, Miranda $Z A$. Pesquisa participante na intervenção da transmissẫo de belmitoses intestinais (Cidade Satélite do Paranoá - Distrito Federal). Revista da Sociedade Brasileira de Medicina Tropical 28:223-232, jul-set, 1995.

menos freqüente "as lombrigas" e mais raramente "a solitária e oxiúro"; e clinicamente pelos seus sintomas já mencionados. De uma maneira geral consideramos que os conhecimentos expressados, foram estereotipados e fragmentados, sem força de interferência no cotidiano das pessoas.

Comparando esses resultados com aqueles obtidos por autores que trabalharam em região com características rurais, de colonização antiga (século passado) e estabilizada (Vila de Santa Eudóxia, interior do Estado de São Paulo $)^{15}$, verificamos diferenças marcantes no que se refere à densidade de conteúdo da maioria das respostas não obstante a boa receptividade das pessoas entrevistadas na duas situações. No trabalho de Santa Eudóxia, verificou-se que: as pessoas utilizavam os serviços de saúde porém a valorização da medicina popular seja na utilização de chás, infusões, benzedeiras e simpatias era muito alta; sabiam fazer acuradamente o diagnóstico clínico; tinham diferentes codificações etiológicas; conheciam a porta de entrada, as fontes de infecção, o habitat e as vias de eliminação. Entretanto, em se tratando das perguntas sobre as medidas preventivas, verificamos, tanto no trabalho de Santa Eudóxia quanto no Paranoá, respostas similares que refletiam recomendações técnicas de manuais traduzindo - "aquisição e repetição de conhecimentos da ciência dos doutores" sem haver introjeção dos mesmos.

A avaliação dos resultados do questionário, foi importante para a orientação do conteúdo programático das ações educativas, onde a ênfase do Tema Gerador, objetivou: o enfoque nas medidas preventivas $e$ de controle direcionadas para modificações das condições ambientais e de condições de vida; a interação da equipe e dos Sujeitos participantes da pesquisa; o uso de uma linguagem adequada que deveria ser utilizada durante as reuniões.

\section{Exames Parasitológicos}

Foram realizados, em todas as quadras definidas na Unidade de Pesquisa, o total de 229 exames parasitológicos. Deste total, como mostra a Tabela 1, 172 exames foram procedentes do Grupo I e 57 do Grupo II. Na Fase 2 (2\% levantamento coprológico) só foi possível reexaminar $72(72 \%)$ crianças do Grupo I e 22 (63\%) do Grupo II, perfazendo o total de $94(41,2 \%)$ exames para pesquisa parasitológica. A ausência das crianças na Fase 2 correspondeu a 28\% (Grupo I) e 37\% (Grupo II) em relação à Fase 1 e teve como causa principal a mudança de algumas famílias do Paranoá

Na Tabela 1, está explicitado os resultados obtidos nos exames fecais. Mas como o enfoque central do Tema Gerador foi relacionado às $\mathrm{HI}$, não consideramos importante declinar na mesma, as espécies de protozoários. No entanto, destacamos que o tratamento foi igualmente realizado em todos os casos positivos de acordo com a espécie de parasita diagnosticada nos exames coprológicos.

Tabela 1. Resultados de exames parasitolögicos de 227 crianças de 0-12 anos (Cidade Satélite do Paranoá/DF., 1993)

\begin{tabular}{lcccr}
\hline & \multicolumn{2}{c}{ Grupo I (\%) } & \multicolumn{2}{c}{ Grupo II (\%) } \\
\cline { 2 - 5 } Espécies de Parasitas & Fase 1 & Fase 2 & Fase 1 & Fase 2 \\
\hline Protozoários* & 56,3 & 58,2 & 63,2 & 73,3 \\
Hymenolepsis nana & 17,5 & 25,5 & 10,5 & 20,0 \\
Ascaris lumbricoides & 15,0 & 10,9 & 15,8 & 6,7 \\
Trichuris trichiura & 3,7 & 5,5 & - & - \\
Taenia sp & 6,3 & - & 10,5 & - \\
Ancilostomideos & 1,2 & - & - & - \\
Total de exames & 100 & 72 & 35 & 22 \\
\hline positivos & 64,0 & 62,5 & 48,6 & 68,2 \\
negativos & 36,0 & 37,5 & 51,4 & 31,8 \\
\hline "Está incluído Giardia lamblia e Entamoeba bistolytica. \\
- Resultados negativos.
\end{tabular}

Analisando essa Tabela, verificamos a alta freqüência de protozoários (juntos Giardia lamblia e Entamoeba complexo bistolytica), seguidos por Hymenolepsis nana e Ascaris lumbricoides.

No total dos exames realizados identificamos: no Grupo I diferenças sensiveis na diminuição dos resultados positivos (menos de 2,5\%) entre as duas Fases, embora não sendo estatisticamente significantes; no Grupo II aumento significativo de resultados positivos (mais de 20\%). Cabe ressaltar que tanto no Grupo I quanto no Grupo II, houve igualmente diferenças na diminuição de positividade em relação a infecção por Ascaris lumbricoides, Taenia sp e Ancilostomideos.

Fazendo uma comparação desses resultados com aqueles obtidos em Santa Eudóxia $^{17}$, verificamos semelhanças no que se refere à queda nos índices de positividade em relação a Ascaris lumbricoides, Taenia sp e $T$. tricbiura e os indices totais. Ressaltamos que em Santa Eudóxia se procederam três tratamentos de 18 meses ( 6 de intervalo) onde apenas no terceiro é que foram registrados 
Mello DA, Martins $C B$, Bittencourt Jr AC, Matos RMC, Pina F, Miranda ZA. Pesquisa participante na intervenção da transmissão de belmitoses intestinais (Cidade Satélite do Paranoá - Distrito Federal). Revista da Sociedade Brasileira de Medicina Tropical 28:223-232, jul-set, 1995.

significativos decréscimos dos indices de positividade, em média $16,2 \%$ a menos em relação ao número total. Ao lado do esquema terapêutico em três etapas, portanto duplamente mais intensivo do que no Paranoá, no trabalho de Santa Eudóxia, não houve grupo controle em relação as ações educativas. Cabe destacar que na situação do Paranoá o Grupo II foi o controle quanto ao papel que ações educativas podem ter interferido na transmissão das HI. Neste sentido, analisando os resultados dos dois Grupos na Tabela 1, podemos sugerir que o tratamento efetuado nas crianças, associado concomitantemente às ações educativas, contribuiu substancialmente para a diminuição dos casos positivos.

\section{Reunioes com os grupos participantes-sujeito}

Foram realizadas um total de 20 reuniões de aproximadamente 52 horas ( 2 a 3 horas de duração cada reunião), para 5 grupos com um total de 57 participantes. A presença de pessoas nas reuniões variou de 9 a 15 por grupo.

a) Um aspecto que primeiro nos chamou a atenção foi o fato de que os participantes tinham pouco ou nenhum relacionamento social entre si, mesmo sendo vizinhos, por isso definimos que a primeira abordagem do trabalho antes de entrarmos com o programa eixo do conteúdo, objetivaria o conhecimento mútuo das pessoas presentes nas reuniões. Assim, procuramos proporcionar um ambiente alegre e descontraído, que facilitasse $o$ desbloqueio das inibições e tensões. As ações conduzidas neste sentido foram desenvolvidas através de técnicas de animação tais como brincadeiras para estimular as apresentações individuais e entrevistas simuladas entre duplas feitas ao acaso ou por escolha. Com essa dinâmica os participantes expressaram: quem eram; o que faziam e as coisas que gostavam; como percebiam a realidade e suas vidas; porque estavam presentes nas reuniões; e o que esperavam do trabalho que estavam participando.

Nesse contexto, é importante o destaque de alguns depoimentos: "Estou aqui para aprender alguma coisa pois é um auxílio para tratar as crianças, eu trabalbo fora o dia todo e não tenbo tempo de ir ao Posto de Saúde que é demorado"; "Fico muito feliz em estar aqui com vocês. Ontem quando cheguei em casa a minha vizinba entregou o bilbete que vocês deixaram lá em casa, fiquei muito feliz e graças a Deus está tudo bem, estou gostando muito de participar das reuniões"; "Teria que ter mais esse tipo de trabalbo com a gente, pois não se tem muita oportunidade de aprender as coisas"; "É uma oportunidade muito boa pra gente que trabalba o dia todo fora de casa"...

b) Para trabalhar o conteúdo programático nas reuniões utilizamos encenação e dramatização das histórias de Vida do Indivíduo e do Paranoá e a Realidade Vivenciada. As apresentações expressaram com muita sensibilidade a saga de indivíduos e famílias migrantes, na busca de condições de Moradia, Educação, Trabalho e Saúde. ("um canto para morar"; "um lugar onde meus filhos possam aprender a ler"; "ficar mais perto de ser atendido pelo médico"; "vim pensando em mais oportunidade de trabalbo").

c) Através de depoimentos, os participantes relataram e analisaram as dificuldades quando chegaram no Patanoá e as lutas enfrentadas para conquistar reivindicações básicas como o Lote, Água, Luz, Esgoto, Asfalto, Praças e Arborização das Ruas, Lazer, Escolas, Postos de Saúde e Transporte Coletivo. Após as discussões concluíram que: "até que muita coisa foi conseguida, mas ainda a gente tem que continuar lutando pelos nossos direitos, pois paga-se impostos como os outros"; "por isso mesmo precisamos ter organização, conscientização e mobilização".

d) Construindo os Mapas Falantes, ao todo 33 produzidos, os participantes abordaram o Tema Saúde relacionando-o sempre com: habitação, urbanização, esgoto, postos de saúde, hospital, médicos, emprego, escolas, um bom serviço de transporte, coleta de lixo e segurança; assim todos poderiam "sentir-se bem, ter higiene do corpo, ter vontade de criar os filhos bem; se alimentar bem; disposição para deixar a casa limpinha para se ter saúde; não sofrer de doença e ser feliz".

e) O Tema Gerador foi sendo introduzido resgatando-se o questionário aplicado no início da pesquisa. Observou-se que seria importante trabalhar os conhecimentos sobre os "vermes" interativamente com os conhecimentos gerais sobre o corpo humano. A dinâmica utilizada nessa etapa foi a participação coletiva no levantamento desses conhecimentos, que iam sendo escritos na 
Mello DA, Martins CB, Bittencourt Ir AC, Matos RMC, Pina F, Miranda ZA. Pesquisa participante na intervenção da transmissão de belmitoses intestinais (Cidade Satélite do Paranoā-Distrito Federal). Revista da Sociedade Brasileira de Medicina Tropical 28:223-232, jul-set, 1995.

lousa e/ou desenhados sobre papéis. Os participantes tinham como tarefa de casa, observar o ambiente doméstico, intradomiciliar e extradomiciliar, procurando identificar aspectos que tivessem a ver com a presença dos "vermes" nas crianças.

\section{Avaliação}

A avaliação da pesquisa e do processo de construção, apropriação e socialização de conhecimentos, foi realizada no final de cada reunião sendo conjunta a confraternização, retomando-se: a análise do material produzido pelos participantes, com destaque às imagens representativas das histórias de vida dos Indivíduos e do Paranoá, e sua interface de compreensão em relação a Saúde como Qualidade de Vida; e os depoimentos verbalizados pelos participantes. As imagens sintetizaram: o diagnóstico da condição de um modus de vida, que é determinado basicamente pelas dificuldades de trabalho digno versus viver com dignidade e não determinado basicamente pelas dificuldades de trabalho digno versus viver com dignidade e não por sobrevivência; a necessidade do Cidadão ter acesso aos bens e serviços que lhes são de direito e a compreensão das HI como um problema importante com consequências para a saúde da criança e que é principalmente determinado por esse modus de vida. As pessoas demonstraram, verbalmente, prazer e satisfação de ter participado das atividades e das tarefas que objetivaram o exercício da prática de observação de campo, de análise e reflexão, com vários depoimentos importantes que expressaram os resultados obtidos como seguem: "foi muito bom saber o que a gente não sabia como cuidar das crianças quando estão com vermes, como é que trata, como ter cuidado para não pegar mais."; "aprendi várias coisas como os vermes e a bigiene, as condições do ambiente, vários tipos de vermes que eu não conbecia."; "tratar dos vermes, não deixar pegar é cuidar da saúde dos filhos, da limpeza dos alimentos, da casa, da água".. "Fui em todas as reunióes e gostei de todas, agradeço pelo trabalbo"; "para mim foram muito importantes as reuniôes vou guardar no meu coraçãozinbo um pedacinho de cada um de vocês"; "eu aprendi a cada reunião e a cada dia eu gostava mais de vocês como amigos e também como educadores que me educaram".
Para concluirmos as discussões, gostaríamos de comentar duas publicações que fazem interessante reflexão crítica quanto à Educação em Saúde e controle de endemias no Brasil.

A primeira ${ }^{6}$, se reporta à crítica institucional com destaque: para a dissociação que ocorre no planejamento de programas de controle, entre as atividades de educação e as medidas técnicas; e também no que se refere a falta de espaço "para a participação real das populações" uma vez que estas são consideradas como Objeto de ação e não como Sujeito. Ressalta ainda a necessidade de reformulação do papel de educador com a proposta "pergunte e ouça para desenvolver junto ... o conhecimento científico e tecnológico unido ao saber vivencial", tendo como base metodológica a pesquisa participante.

A segunda publicaçâo ${ }^{12}$ analisa duas experiências (controle das Parasitoses Intestinais e do Vetor do virus da Dengue) de ações práticas processuais, na construção, apropriação e socialização de conhecimentos à partir de necessidades do cotidiano, sentidas e expressas por segmentos diversos da comunidade. Essas experiências têm importantes referências em comum tais como: - papel da escola como instituição mediadora e de interação com a comunidade; a valorização da participação quando a comunidade compartilha integradamente do trabalho; o diálogo para a construção conjunta de um novo saber resultante do confronto do saber científico e técnico versus o vivencial, objetivando o estímulo à reflexão crítica assim como a instrumentalização da ação de Cidadania para a conquista de Qualidade de Vida.

$\mathrm{Na}$ investigação de intervenção no controle da HI no Paranoá/DF, cuja base metodológica foi a pesquisa participante ${ }^{3}$, pudemos perceber com clareza que é possivel, mesmo considerando a adversidade do contexto ambiental em função do dinamismo de assentamento urbano recente, trabalhar com um tema específico percebido e reconhecido como importante pelos segmentos Sujeitos da Unidade de Pesquisa. No processo de desenvolvimento da investigação - equipe $e$ participantes juntos - a construção, apropriação e socialização de conhecimentos, se efetivaram através do diálogo como "fato 
Mello DA, Martins CB, Bittencourt Jr AC, Matos RMC, Pina F, Miranda ZA. Pesquisa participante na intervenção da transmissão de belmitoses intestinais (Cidade Satélite do Paranoá - Distrito Federal). Revista da Sociedade Brasileira de Medicina Tropical 28:223-232, jul-set, 1995.

político" ao se proceder a análise e a reflexão crítica de histórias e situações cotidianas de vida, identificando os elementos determinantes que levam a carência de Saúde, e especificamente àqueles responsáveis pela ocorrência do problema específico gerador da pesquisa, i. é., das HI. O conhecimento produzido, aprendido e apreendido, sensibilizou a conscientização dos Sujeitos e a necessidade de organização e participação social para, exercendo a Cidadania, lutar por melhores condições de vida onde o direito de se ter Saúde se faz presente.

\section{SUMMARY}

This work was developed in the Paranoa city town of the Federal District of Brazil. It used technitques of participative research with the aim of reducing intestinal belmintbs transmission in a group of children at nutritional risk. The family nucleus, that is, parents, children and otber relatives living together in the same bouse, was used as reference for this research. All steps of the work were followed simultaneously by technical and educative actions. The technical actions were related to faecal examinations and medication. The educative process, stimulated critical analysis and reflections on the central problem and life conditions, with a strong focus on Healtb Promotion to improve life quality, as well as an empowerment process. During the work development, of the action program included the following steps: bome visits, interviews, group meetings, feedback on the faeces examinations results and treatment. An evaluation of the final results was made through quantitative and qualitative methods, which showed the construction, acquisition and socialisation of knowledge.

Key-words: Intestinal parasites control. Healtb and Education. Intestinal parasites epidemiology.

\section{REFERÊNCIAS BIBLIOGRÁFICAS}

1. Botero B. Possibilidades de control de las geohelmintiases mediante tratamientos en masa. Boletin Chileno de Parasitologia 34:39-47, 1981.

2. Brandão $C R$. O que é o método de Paulo Freire. Editora Brasiliense, $9^{\mathrm{a}}$ edição, 1985.

3. Brandão CR, Oliveira RD, Oliveira MD, Freyre P, Borda OF, Sales IC. Pesquisa Participante. Editora Brasiliense. $4^{\text {a }}$ edição. 1984.

4. Bundy DAP. New iniciatives in the control of helminths. Transactions of the Royal Society of Tropical Medicine and Hygiene 84:467-468, 1990.
5. Cabrera BD, Primo VA, Portillo GP. Ascariasis control and/or eradication in a rural community in the Philippines. Southeast Asian Journal Tropical Medicine Public Health 6:510-518, 1981.

6. Carmo EM. Educação em Saúde no controle das endemias. Memórias do Instituto Oswaldo Cruz 82:293-294, 1987.

7. Crompton DWT, Nesheim MC, Pawlowski ZS, editors. Ascariasis and its Prevention and Control. Taylor \& Francis, 1989.

8. Guyatt HL, Evan D. Economic considerations for helminth control. Parasitology Today 8:397-401, 1992.

9. Hall A, Anwar KS, Tomkins AM. Intensity of reinfection with Ascaris lumbricoides and its implications for parasite control. The Lancet 339:1253-1265, 1992.

10. Halloran ME, Bundy DAP, Pollit E. Infections disease and the UNESCO basic initiative. Parasitology Today 5:359-362, 1989.

11. Jancloes MF, Ernst P, Thienpont D. Mass control of Ascariasis with single oral doses of levamisole: a controlled comparison in 3,056 subjects between three incomplete population coverages. Tropical Geographical Medicine 31:111-112, 1979.

12. Mello DA, Carmo EM. Health Education in Community Programes. Consideration on the process of construction, acquisition and socialization of knowledge. Health \& Social Care in the Community $2: 261-262,1994$.

13. Mello DA, Garrison JL. Reflexões sobre processos de ação prática em Promoção à Saúde. Cadernos de Extensão/Decanato de Extensão Universidade de Brasília, 1993.

14. Mello DA, Pedrazzani ES, Pizzigatti CP. Helmintoses Intestinais: $O$ processo de comunicação e informação no programa de educação e saúde em verminose. Cadernos de Saúde Pública 8: 77-82, 1992.

15. Mello DA, Pripas S, Fucci M, Santoro MC, Pedrazzani ES. Helmintoses Intestinais: I Conhecimentos, atitudes e percepção da população. Revista de Saúde Pública 22:140-149, 1988.

16. Organization Mondial de la Santé. Groupe scientifique des infections intestinales à Protozoaires et à Helminthes. Genève 1980. Séries Rapport Techniques 666, 1982.

17. Pedrazzani ES, Mello DA, Pizzigatti CP, Pripas S, Fucci M, Santoro MCM. Helmintoses Intestinais: II 
Mello DA, Martins CB, Bittencourt Jr AC, Matos RMC, Pina F, Miranda ZA. Pesquisa participante na intervenção da transmissão de belmitoses intestinais (Cidade Satélite do Paranoá - Distrito Federal). Revista da Sociedade Brasileira de Medicina Tropical 28:223-232, jul-set, 1995.

- Prevalência e correlação com renda, tamanho família, anemia e estado nutricional. Revista de Saúde Pública 22: 384-389, 1988.

18. Pedrazzani ES, Mello DA, Pizzigatti CP, Pripas S, Fucci M, Santoro MCM. Helmintoses Intestinais: III - Programa de educação e saúde em verminose. Revista de Saúde Pública de São Paulo 23: 189-195, 1989.

19. Seminário Sobre Educação em Saúde. Divisão Nacional de Educação em Saúde/Ministério da Saúde - Brasília 01-04 agosto, 1989.
20. Wright MGA, Rosa ZT, Alves ED, Alencar AGA, Araújo AAB, Salles SP, Pinto VB, Mello DA. Promoção integral de Saúde-Nutrição na comunidade do Paranoá/DF. III - Vivência crítica de uma experiência com promotores de Saúde. In: Anais do $2^{\circ}$ Congresso Brasileiro de Saúde Coletiva, p.119, 1992. 